\title{
Obituaries
}

Editor: Henry R. Rollin

\section{Derek Russell. Davis, Emeritus Professor of Mental Health, Bristol University}

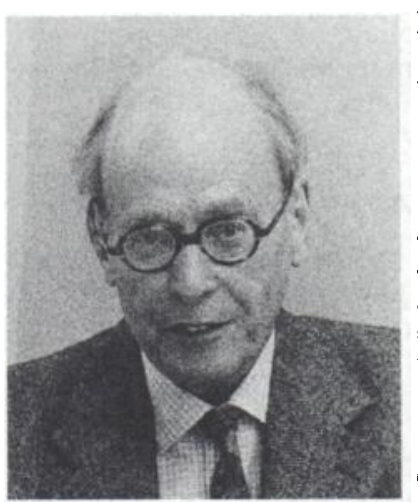

Professor Derek Russell Davis was born on 20 April 1914 and died on 3 February 1993. He was educated at Stowe School and read medicine at Clare College, Cambridge where he graduated BA in 1935 and then took his MA in 1939. His clinical studies were completed at the

Middlesex Hospital, London. He qualified MB BChir (Cantab) in 1939 and was awarded the MD in 1946. In 1963 he was elected FRCP and a Foundation Fellow of the Royal College of Psychiatrists in 1971.

He resumed his long association with Cambridge when in 1940 to 1948 he was appointed a member of the MRC scientific staff at the Psychological Laboratory. From 1950 to 1958 he served as Reader in Clinical Psychology, and from 1958 to 1962 as Director of the Medical Psychology Laboratory and Reader in Medical Psychology in the University of Cambridge.

Derek Russell Davis established his scientific reputation through his work as a medical psychologist in Cambridge during the 1939-45 war. He studied the effects of fatigue on pilot error and explored the psychology of stress. In 1948 he resumed his psychiatric practice as a consultant at Fulbourn and Addenbrooke's and taught psychopathology to undergraduates. His book $A n$ Introduction to Psychopathology, based on his lectures, ran to four editions. During his time at Cambridge he also became interested in the psychological organisation of the family and in disorders of intellectual development.

At Bristol he encouraged a multidisciplinary approach among his students and staff. He challenged the accepted view that the proper place for the psychiatrist to practise was in the mental hospital and established his new department in the heart of the teaching hospital. From the moment that I joined his team at the Bristol Royal Infirmary as a young trainee I became aware that his approach was radically different from anything I had previously known. Derek was a stimulating teacher and his clinics and ward rounds were always lively occasions. His optimism, his wry sense of humour and his delight in challenging orthodox opinions combined to provide a unique experience for those who were trained by him.

He set up the first comprehensive psychiatric service with the United Bristol Hospitals and organised systematic teaching for medical students at a time when such courses were still novel. In his clinics at the Bristol Children's Hospital he enjoyed a close relationship with his friend John Apley, a like minded paediatrician, who shared his interest in psychosomatic disorders in children. He was a good listener and enjoyed his work with individuals and families.

The expansion of the universities in the mid 1960 s provided an opportunity to incorporate new ideas in medical education. Derek seized the chance to introduce behavioural science into the medical curriculum and established a course which soon became a model for other medical schools. From 1970-1972 he was Dean of the Faculty of Medicine. He made a major contribution to the development of psychiatric services throughout the West Country. He did much to raise the standards of postgraduate training. Although he retired from the university in 1979 he continued in practice until his final illness.

Derek Russell Davis had an extraordinarily wide range of interests. He was a champion of mental health reforms and was a member of the council of management of MIND for over 25 years. Never afraid of being controversial he was often called upon to advise on the ethics of psychiatric treatment. He had an abiding interest in the theatre and frequently illustrated his ideas about psychological processes in families by examples from Ibsen and Shakespeare. In his last book, Scenes of Madness: a psychiatrist at the theatre, he showed that mental health professionals could learn much from playwrights and commented: "Artists are the explorers, scientists the map makers." Derek was both explorer and map maker; therapist and scientist, he will be greatly missed.

$\mathrm{He}$ is survived by his wife, Marit, and by Jan and Vivien, his son and daughter.

Oliver Russell 